UDC 316.3

LBC 60.56

\title{
ETHNO-RELIGIOUS CHARACTER OF URBAN SPACE IN THE CONTEXT OF SOCIAL AND CULTURAL STABILITY IN AN INSTABLE MULTI-ETHNIC REGION ${ }^{1}$
}

\author{
Galina D. Gritsenko \\ Stavropol State Medical University, Stavropol, Russian Federation; \\ Federal Research Centre The Southern Scientific Centre of the Russian Academy of Sciences, \\ Rostov-on-Don, Russian Federation
}

\begin{abstract}
The author considers the dynamics of ethno-religious interactions of representatives of different nationalities in the predominantly Russian-speaking regional community. As a result of establishing the North Caucasus Federal district, the local ethno-cultural and religious landscapes of the urban space of the Stavropol territory were reconfigured. According to sociological studies, due to qualitative changes in the structure of the ethno-religious landscape in the first decade of the twenty-first century, ethnicity and religiosity acquired a conflictogenic character and provoked ethno-confessional conflicts in the urban environment. The article shows that socio-cultural factors played a significant role among the conflict factors. First and foremost, it is the simplification of the education system, manifested in formation of unscholarly youth, and clericalization of the regional component in education leading to decline in teaching of the Russian language in the North Caucasus republics, to ethnic interpretations of historical events, to the increase of number of young people who do not know the state language. The decline in the level of education of some of the natives of the North Caucasian republics was manifested in the aggravation of interethnic and interfaith interactions between the indigenous inhabitants of the urban environment and natives of the republics of the North Caucasus. Destabilizing ethnoconfessional relations factor is the frequent use of the national (non-Russian) language in public places of traditionally Russian-speaking environment.

The article reveals the joint activities of the authorities and civil society institutions, primarily diasporas and religious organizations, to give ethnicity and religiosity a peacemaking content, to ensure a conflict-free ethnoreligious situation, to reduce tensions in the sphere of ethnic and religious relations. As a result of this work, sociocultural stability was achieved in the urban space of the multi-ethnic region. At the same time, the study of the ethno-religious landscape of the urban environment indicates the presence of potential conditions for the emergence of new conflict-related threats, one of which may be neophism. This situation requires the development of a clear algorithm of actions to prevent radicalism among neophytes. The ethno-religious landscape of the urban space of the Stavropol territory is contradictory: socio-cultural stability in the multi-ethnic region is supported by joint actions of authorities and civil society institutions, but the mosaic of the ethno-religious landscape is used by radical forces to spread radicalism and ethno-confessional conflicts.
\end{abstract}

Key words: ethnicity, religiosity, urban environment, multi-ethnic region, conflict, stability, North Caucasus.

УДК 316.3

ББК 60.56

\section{ЭТНОРЕЛИГИОЗНОСТЬ ГОРОДСКОГО ПРОСТРАНСТВА В КОНТЕКСТЕ СОЦИОКУЛЬТУРНОЙ СТАБИЛЬНОСТИ В НЕСТАБИЛЬНОМ ПОЛИЭТНИЧНОМ РЕГИОНЕ ${ }^{1}$}

\section{Галина Дмитриевна Гриценко}

Ставропольский государственный медицинский университет, г. Ставрополь, Российская Федерация; Федеральный исследовательский центр Южный научный центр РАН, г. Ростов-на-Дону, Российская Федерация 
Аннотация. В статье рассматривается динамика этнорелигиозных взаимодействий представителей разных национальностей в преимущественно русскоязычном региональном сообществе. В результате создания Северо-Кавказского федерального округа произошла переконфигурация локальных этнокультурных и религиозных ландшафтов городского пространства Ставропольского края. Согласно данным социологических исследований из-за качественных изменений структуры этнорелигиозного ландшафта в первое десятилетие XXI века этничность и религиозность приобрели конфликтогенный характер и спровоцировали этноконфессиональные конфликты в городской среде. В статье показано, что среди конфликтогенных факторов значительную роль играли социокультурные. К ним, прежде всего, относятся примитивизация системы образования, проявляющаяся в формировании неэрудированной молодежи, и клерикализация регионального компонента в образовании, ведущая к этническим трактовкам исторических событий, ухудшению преподавания русского языка в северокавказских республиках, росту числа молодых людей, плохо знающих государственный язык. Снижение уровня образованности у части выходцев из северокавказских республик проявилось в обострении межэтнических и межконфессиональных взаимодействий коренных жителей городской среды и выходцев из республик Северного Кавказа. Дестабилизирующим этноконфессиональные отношения фактором стало частое использование национального (нерусского) языка в общественных местах традиционно русскоязычной среды.

В статье раскрыта совместная деятельность органов власти и институтов гражданского общества, прежде всего диаспор и религиозных организаций, по приданию этничности и религиозности миротворческого содержания, обеспечению бесконфликтной этнорелигиозной ситуации, снижению напряженности в сфере этнических и религиозных отношений. В результате проведенной работы была достигнута социокультурная стабильность в городском пространстве полиэтничного региона. В то же время исследование этнорелигиозного ландшафта городской среды свидетельствует о наличии потенциальных условий для возникновения новых конфликтогенных угроз, одной из которых может стать неофизм. Такая ситуация требует разработки четкого алгоритма действий по профилактике радикализма среди неофитов. Этнорелигиозный ландшафт городского пространства Ставропольского края противоречив: социокультурная стабильность в полиэтничном регионе поддерживается совместными действиями органов власти и институтов гражданского общества, однако мозаичность этнорелигиозного ландшафта используется радикально настроенными силами для распространения радикализма и провоцирования этноконфессиональных конфликтов.

Ключевые слова: этничность, религиозность, городская среда, полиэтничный регион, конфликтность, стабильность, Северный Кавказ.

Ставрополь и Ставрополье всегда характеризовались многонациональностью, полиэтничностью, многоконфессиональностью. Территориальная близость с буддистской Калмыкией, мусульманским Северным Кавказом, армяно-григорианской Арменией и т. д. не могла не сказаться на структуре этнического и религиозного ландшафта регионального пространства. Так, согласно Всероссийской переписи населения, проведенной в 2010 г., национальный состав населения Ставрополья представлен более чем 50 этносами, народами и народностями. Кроме русских, составляющих $80,1 \%$ от общей численности населения Ставропольского края, значительными по численности национальностями являются армяне, даргинцы, греки, цыгане, украинцы, ногайцы, азербайджанцы, карачаевцы, чеченцы, татары, туркмены, грузины, немцы, осетины, аварцы, кабардинцы, лезгины, кумыки, черкесы и др. [Итоги Всероссийской переписи... web]. В крае насчитывается около 440 религиозных организаций, представляющих разные вероисповедания [Религия и национальности web].

В связи с образованием Северо-Кавказского федерального округа в 2010 г. и вхождением в его состав Ставропольского края серьезно изменился этнический и религиозный ландшафт городов Ставрополья, выросла их этноконфессиональность. Увеличилось число армян, даргинцев, чеченцев, карачаевцев, адыгов, абазинов и др. У жителей северокавказских республик возрос интерес к городам края как к территории инвестирования, развития предпринимательства, бизнеса и где на относительно высоком уровне организованы социальные процессы - образование и наука, лечение и профилактика, отдых и досуг и т. д. В частности, наблюдается приток в ставропольские города представителей титульных этнических групп северокавказских республик для занятий бизнесом и предпринимательством. На рынке жилья в городах края все 
активнее фигурируют жители республик СКФО. Увеличивается число студентов из соседних республик (каждый третий студент является выходцем из северокавказских республик), многие из которых после окончания ставропольских учебных заведений стремятся остаться в городах края и найти здесь работу [Гриценко, Маслова 2018, 105]. В результате в городском пространстве края произошли качественные структурные изменения: оно стало еще более этнически и конфессионально пестрым.

В результате переструктурирования этнокультурного и религиозного ландшафтов городского пространства произошло резкое обострение этноконфессиональных взаимодействий старожильского населения и мигрантов, о чем свидетельствуют результаты различных социологических исследований [Матишов (ред.) 2012, 307-320]. Так, с 2006 г. по 2012 г. в три раза увеличилась доля тех ставропольчан-респондентов, кто считал, что межнациональные отношения в регионе характеризуются напряженностью и даже конфликтностью: с 17,5 \% в 2006 г. до 50,5 \% в 2012 году. Возросла также доля участников опроса, прогнозировавших ухудшение отношений между людьми различных национальностей в ближайшие 2-3 года: соответственно с 22,2 \% до 60,5\%. Достаточно высока и доля тех, кто был убежден, что взаимодействие людей разных национальностей есть источник неприятностей $(35,3 \%$ и 37,0 \%) [Матишов (ред.) 2012, 310]. Данная ситуация сохранилась и в 2016 г.: этничность и религиозность по-прежнему имели конфликтогенное содержание [Авксентьев и др. 2017].

Полученные в ходе исследований (20062016 гг.) результаты вызвали «недоумение»вопрос: почему для Ставрополья и в частности городского пространства, где традиционно проживало много неславянских неправославных этносов, серьезной проблемой стали этноконфессиональные взаимодействия, обусловливающие этнокультурную нестабильность в исторически полиэтничном регионе.

Анализ результатов исследований этноконфессионального ландшафта СКФО позволил не только ответить на этот вопрос, но и выстроить иерархию факторов, провоцирующих этнокультурные и религиозные конфликты в ставропольской городской среде.
Безусловно, среди конфликтогенных факторов в полиэтничном городском пространстве были выявлены и экономические, и социальные, и политические. Однако представляет интерес мнение эксперта о приоритетной роли социокультурных факторов в снижении этнорелигиозной стабильности в региональном сообществе. «Гораздо важнее и существеннее, - отмечают эксперты, - является все возрастающий социокультурный диссонанс, который все явственнее обозначает себя в процессе взаимодействия между мусульманским и немусульманским сегментами северокавказского социума. При этом данная тенденция будет только возрастать» [Авксентьев и др. 2017, 117].

Одной из основных причин приобретения этничностью и религиозностью в городском пространстве полиэтничного края конфликтогенного содержания является, по мнению опрошенных специалистов, система образования, которая «...ничем не отличается от общероссийской» и в которой «заложена конфликтогенность, проявляющаяся в примитивизации образования и формировании ограниченной и неэрудированной молодежи, не способной понять за счет своей ограниченности всего разнообразия мира и свое место под солнцем $<\ldots>$. Знания и их реальная ценность нивелируются в связи с общим регрессом высшего и школьного образования по всей стране и практическим отсутствием среднего профессионального образовательного звена, которое разрушено и уничтожено системой реформ» [Авксентьев и др. 2017, 118].

Другой значимой причиной социокультурной нестабильности в этнорелигиозной городской среде, как полагают эксперты, выступает клерикализация регионального компонента в образовании. Это неизбежно ведет, по утверждению экспертов, к этническим трактовкам разных исторических событий, ухудшению преподавания русского языка и, следовательно, к росту числа молодых людей, плохо знающих государственный язык [Авксентьев и др. 2017, 118].

Именно поэтому на первое место в 20102013 гг. среди обстоятельств, негативно влияющих на взаимодействие людей, принадлежащих к разным этноконфессиональным сообществам, вышли искаженные формы пози- 
ционирования частью мигрантов и прежде всего молодежью национальных и религиозных традиций. Так, в течение 2010-2013 гг. на территории города Ставрополя произошло несколько резонансных эпизодов «выполнения» национальных традиций. Это и выстрелы в воздух из травматического пистолета и исполнение лезгинки на перекрестке магистральных улиц столицы края [Дроботов web2]; это и исполнение в два часа ночи в центре города лезгинки, которое сопровождалось нецензурной бранью, хлопаньем в ладоши, стрельбой из травматического оружия [В Ставрополе задержаны... web]; это и организация национальных танцев на улицах ночного города в страстную пятницу [Дроботов web1]. Перечень таких ситуаций можно продолжить и найти в городской среде других городов края, в частности, в столице Северо-Кавказского федерального округа - г. Пятигорске. Безусловно, участники подобных инцидентов были привлечены к разным видам административной ответственности, но «не за сам танец, а за нарушение общественного порядка, выразившееся в явном неуважении к обществу и нецензурной брани» [Арестованы танцоры... web].

Однако такие, как правило, «ночные» танцы, неизбежно приводили не только к негативному восприятию местным населением молодых представителей северокавказского сообщества, но и к более трагическим событиям - к самосуду. Во время одного из таких эмоционально шумных представлений к молодым людям подошла группа мужчин в масках и молча начала расстреливать танцующих из травматического оружия. В итоге двое из веселившейся компании обратились за медицинской помощью [Сазонов web]. Так, традиционный народный танец, распространенный по всему Кавказу [Николаев web], превратился в фактор этноконфессионального конфликта.

Еще одним проявлением этнорелигиозных традиций, которое, по мнению экспертов, в 2010-2016 гг. являлось фактором разъединения людей по этническому и конфессиональному признакам, стало массовое появление в городском пространстве исторически немусульманского населения девушек в хиджабах [Дроботов web2]. При этом важно отметить, что взрослые женщины-мусульманки, приез- жающие на время на территорию Ставрополья из северокавказских республик или проживающие здесь постоянно, не носят этот атрибут религиозной одежды, хотя, как правило, носят головной убор - платок.

Переконфигурация локальных религиозных ландшафтов городского пространства проявилась и в незаконном строительстве мечетей в Пятигорске и Кисловодске (2013 г.). Этот факт приобрел конфликтогенное содержание и привел к обострению этноконфессиональных взаимодействий в городской среде [В Кисловодске... web; Администрация Пятигорска... web].

Из-за качественных изменений структуры этнорелигиозного ландшафта городского пространства Ставрополья вторым по значимости фактором, дестабилизирующим этноконфессиональные отношения, стало частое использование национального (нерусского) языка в общественных местах традиционно русскоязычной среды. Так, в ходе социологического опроса было установлено, что с 2006 г. по 2012 г. выросла доля тех коренных жителей-ставропольчан, которые испытывают напряженность, когда слышат вокруг себя чужую речь: с 29,1 \% до 57,5 \% респондентов [Матишов (ред.), 318]. Как отмечают эксперты, в советское время практически все, кто приезжал учиться или работать в край из республик Северного Кавказа, достаточно хорошо владели русским языком. Сконцентрированное в ограниченном городском пространстве использование нерусского языка стало вызывать у местных жителей ощущение нахождения не в родном городе, а на территории одной из северокавказских республик, и как следствие - то негативное восприятие инонационального и инорелигиозного, о котором свидетельствуют данные соцопроса [Maтишов (ред.), 318]. Даже те молодые люди, которые поступали в вузы края, нередко плохо говорили по-русски и, как правило, не предпринимали активных усилий для овладения языком, на котором идет процесс обучения русским. В ситуации слабого владения русским языком студенты из северокавказских республик предпочитали говорить на своем родном языке. Поскольку таких молодых людей достаточно много, то даже в коридоpax вузов возникало ощущение, что находишь- 
ся не в ставропольском вузе, а в одном из университетов северокавказской республики.

Осознавая возможные негативные последствия для межэтнических и межрелигиозных отношений, существующих в региональном сообществе, дестабилизирующих факторов, руководство региона и диаспор, представители общественных, религиозных и политических организаций сконцентрировали свое внимание на обеспечении социокультурной стабильности в этноконфессиональной среде региона. В частности, при губернаторе края был создан Совет по вопросам межэтнических отношений как диалоговая площадка, на которой региональная власть и представители институтов гражданского общества открыто стали обсуждать проблемы, имеющиеся в области межнациональных и межконфессиональных отношений, разрабатывать пути эффективного решения вопросов, возникающих в ходе формирования межэтнического согласия [Сергушина web]. Одним из позитивных результатов совместной деятельности органов власти и институтов гражданского общества стала программа «Межнациональные отношения, профилактика терроризма и поддержка казачества», на осуществление мероприятий которой в 2018 г. было направлено 6 миллионов 300 тысяч рублей. Среди наиболее значимых мероприятий следует назвать научно-методический форум для руководителей национально-культурных объединений городских округов, межэтническая акция «Победа одна на всех», в рамках которой в музее «Россия. Моя история» был показан фильм «Бесленей. Право на жизнь» о спасении в черкесском ауле в годы оккупации 32 детей из блокадного Ленинграда [Религия и национальности web].

Известно, что особенностью городского пространства столицы края является то, что Ставрополь - молодежный город и столица студенчества всего Северо-Кавказского федерального округа. Каждый четвертый ставропольчанин - это студент высшего или среднего специального учебного заведения. С целью активизации воспитательного процесса среди молодежи, главным образом среди студенчества, была организована работа Консультативного совета, в который вошли руководители всех 35 национально-культурных организаций, атаманы 12 городских казачьих обществ, представители 12 религиозных объединений, сотрудники правоохранительных органов, члены научных сообществ. Под эгидой Консультативного совета ведется работа по социокультурной адаптации студентов, приехавших в краевую столицу из разных уголков Северного Кавказа. Также организована индивидуальная работа с молодыми людьми, кто наиболее подвержен или подпал под действие идеологии терроризма и экстремизма. Кроме того, сформирована кибердружина из студентов, осуществляющих мониторинг сети Интернет с целью выявления опасных для молодежи сайтов, пропагандирующих терроризм, экстремизм, наркотики, суицид. Сформирован Молодежный этнический совет при администрации города Ставрополя, позитивная деятельность которого способствует консолидации молодежи разных национальностей и религий, что позволило обеспечить активное участие всех национально-культурных объединений в организации и проведении XXVI Всероссийского фестиваля «Российская студенческая весна - 2018» и III Международного фестиваля «Студенческая весна стран БРИКС и ШОС - 2019».

Для более продуктивного взаимодействия городских национально-культурных и этноконфессиональных организаций, выстраивания диалога между ними в 2014 г. создан Ставропольский городской Дом Дружбы, на территории которого открыт музей народов, проживающих в Ставрополе. Здесь организованы занятия по изучению абазинского, армянского, греческого и грузинского языков, формируются группы по изучению черкесского и кабардинского языков [Религия и национальности web].

В Северо-Кавказском федеральном университете, где учится более $20 \%$ от общей численности студентов представителей республик Северного Кавказа, одним из приоритетных направлений деятельности является укрепление ведущей роли русского языка в формировании общероссийской идентичности [Левитская 2014].

Кропотливая и целенаправленная деятельность различных акторов по формированию и сохранению социокультурной стабильности, гармонизации локальных этнокультур- 
ных и религиозных ландшафтов в городской среде, урегулированию потенциальных этноконфессиональных конфликтов дала свои позитивные результаты. Согласно данным социологического исследования доля населения, положительно оценивающего состояние этноконфессиональных отношений в региональном пространстве, увеличилась за последние пять лет более чем в три раза: с $26,9 \%$ до $94,7 \%$ [Сергушина web].

Данная тенденция была зафиксирована результатами и других социологических исследований [Гриценко, Маслова 2018]. Около $70 \%$ респондентов, являющихся студентами вузов г. Ставрополя, указали, что они в сфере межкультурной коммуникации придерживаются мировоззренческой установки на «толерантное отношение к представителям иной (этнической, религиозной) культуры» [Гриценко, Маслова 2018, 105].

Однако сегодняшний процесс позитивного преобразования этнокультурных и религиозных ландшафтов городского пространства с точки зрения обеспечения социокультурной стабильности и снижения напряженности в сфере этнических и религиозных взаимодействий стал осложняться новой проблемой, которая в последнее время приобрела особую остроту. Это неофизм. В действительности, неофизм не содержит ничего антиобщественного или противозаконного: это проявление реализации права граждан на свободу вероисповедания. Но социальная практика показывает, что нередко неофиты переходят на путь террора. Как считает советник муфтия Ставропольского края М. Магомедов, превращение неофита в радикала происходит часто не по воле самого человека: «мотивы у тех, кто приходит в ислам, ранее не имея отношения к нему, разные, - полагает Магомедов, - но итог зачастую оказывается один: новообращенные, попадая к радикалам, перестают думать самостоятельно, становятся зависимыми от других, что и позволяет навязать им самые радикальные версии познания бога» [Тимченко 2018]. При этом среди неофитов появляются девочки 7 11-х классов. И здесь важно понять причины, по которым человек меняет религию, к чему он готовится или его готовят. И вновь следует вести речь о выработке четкого ал- горитма работы по профилактике радикализма среди неофитов [Неофиты... web].

Таким образом, для этнорелигиозного ландшафта городского пространства Ставропольского края характерна противоречивость: с одной стороны, власти совместно с институтами гражданского общества удалось придать этничности и религиозности миротворческий потенциал и обеспечить социокультурную стабильность в полиэтничном регионе, что проявляется в отсутствии в течение последних лет этноконфессиональных конфликтов. С другой стороны, радикально настроенные силы используют мозаичность этнорелигиозного ландшафта для распространения радикального ислама. Разноплановость применения этнорелигиозного фактора в социокультурных процессах полиэтничного региона указывает на необходимость постоянного социологического сопровождения этнокультурных процессов, религиозных взаимодействий и прогнозирования последствий их развития.

\section{СПИСОК ЛИТЕРАТУРЫ}

Авксентьев и др. 2017 - Авксентьев В.А., Гриценко Г.Д., Лепилкина О.И., Шульга М.М. Северный Кавказ: нестабильная стабильность // Наука Юга России. 2017. Т. 13. № 1. С. 115-125.

Администрация Пятигорска... web - Администрация Пятигорска подала иск о сносе незаконно возведенной мечети [КМВСИТИ] // https:/ /news.kmvcity.ru/2013/09/10/administraciyapyatigorska-podala-isk-o-snose-nezakonnovozvedennoi-mecheti/42376.

Арестованы танцоры... web - Арестованы танцоры, нарушавшие общественный порядок города [News 1777] // http://news.1777.ru/4455arestovany-tancory-narushavshie.html.

В Кисловодске... web - В Кисловодске снесут две мечети, построенные вместо жилых домов [Комсомольская правда. 06.08.2013] // https:// www.kirov.kp.ru/daily/26115/3010339.

Итоги Всероссийской переписи... web - Итоги Всероссийской переписи населения 2010 года в отношении демографических и социальноэкономических характеристик отдельных национальностей // https://www.gks.ru/free_doc/ new_site/perepis2010/croc/results2.html.

Гриценко, Маслова 2018 - Гриценко Г.Д., Маслова Т.Ф. Взаимодействие студентов в поликультурном образовательном пространстве // Kant. 2018. № 3 (28). C. 103-107. 
Дроботов webl - Дроботов А. Арестованный танцор лезгинки в Ставрополе: «Мы танцевали не в Кремле, а у себя дома» [Комсомольская правда. 18.01.2013] // https://www.stav.kp.ru/daily/ $26016 / 2939054$

Дроботов web2 - Дроботов А. На Ставрополье продолжается скандал с хиджабами [Комсомольская правда. 30.11.2012] // https://www.stav.kp.ru/ daily/25993/2923301.

Левитская 2014 - Левитская А.А. СКФУ: Политика форсированного роста // Аккредитация в образовании. 2014. № 5 (73). С. 48-53.

Матишов (ред.) 2012 - Матишов Г.Г. (ред.). Проблемы социально-экономического и этнополитического развития южного макрорегиона. Ростов-н/Д: ЮНЦ РАН, 2012.

Неофиты... web - Неофиты на Ставрополье стали серьезной проблемой. Ставрополье [TV. 2018. 20 июня] // https://stavropolye.tv/news/state/ 112102 .

Николаев web - Николаев $K$. Мария Захарова станцевала лезгинку на молодежном форуме «Машук-2019» [Вечерняя Москва. 22.08.2019] // https://vm.ru/news/741851-mariya-zaharovastancevala-lezginku-na-molodezhnom-forumemashuk-2019.

Религия и национальности web - Религия и национальности [Портал органов государственной власти Ставропольского края] // http:// www.stavregion.ru/stat/social/religion.

Сазонов web-Сазонов Е. В Ставрополе расстреляли танцоров лезгинки [Русский обозреватель. 2013. 8 августа] // http://www.rus-obr.ru/ru-web/26008.

Сергушина web-Сергушина Г. 95 из 100 жителей Ставрополья положительно оценивают состояние межнациональных отношений [MК - Кавказ. 26 июня 2018] // https://kavkaz.mk.ru/social/2018/ 06/26/pravitelstvo-stavropolskogo-kraya-sumelodobitsya-realnykh-uspekhov-v-garmonizaciimezhnacionalnykh-otnosheniy-v-regione.html.

В Ставрополе задержаны... web - В Ставрополе задержаны матерившиеся танцоры лезгинки. [Ставрополье.TV] // https://stavropolye.tv/ news $/ 35300$.

Тимченко 2018 - Тимченко М. Самые несчастные мусульмане. Почему неофиты выбирают радикальный ислам [Аргументы и Факты. 2018. № 31. 6 августа] // https://stav.aif.ru/society/ person/samye_neschastnye_musulmane pochemu_neofity_vybirayut_radikalnyy_islam.

\section{REFERENCES}

Avksentyev V.A., Gritsenko G.D., Lepilkina O.I., Shulga M.M., 2017. North Caucasus: unstable stability.
Science of the South of Russia, vol. 13, no. 1, pp. 115-125.

The administration of Pyatigorsk filed a lawsuit to demolish the illegally erected mosque. KMVSITI. URL: https://news.kmvcity.ru/2013/09/10/ administraciya-pyatigorska-podala-isk-o-snosenezakonno-vozvedennoi-mecheti/42376 (accessed 20 April 2019).

Dancers who violated the public order of the city were arrested. News 1777. URL: http://news.1777.ru/ 4455-arestovany-tancory-narushavshie.html (accessed 20 April 2019).

In Kislovodsk demolish two mosques built instead of houses. Komsomolskaya Pravda, 06.08.2013. URL: https://www.kirov.kp.ru/daily/26115/ 3010339 (accessed 27 April 2019).

Results of the 2010 All-Russian population census with regard to demographic and socio-economic characteristics of individual nationalities. URL: https://www.gks.ru/free_doc/new_site/ perepis 2010/croc/results $2 . \mathrm{html}$ (accessed 27 April 2019).

Gritsenko G.D., Maslova T.F., 2018. Interaction of students in multicultural educational space. Kant, no. 3 (28), pp. 103-107.

Drobotov A. Arrested lezginka dancer in Stavropol: "We danced not in the Kremlin, and at home". Komsomolskaya Pravda, 18.01.2013. URL: https://www.stav.kp.ru/daily/26016/2939054 (accessed 27 April 2019).

Drobotov A. In the Stavropol region continues scandal hijab. Komsomolskaya Pravda, 30.11.2012. URL: https:/www.stav.kp.ru/daily/25993/2923301 (accessed 20 April 2019).

Levitskaya A.A., 2014. North Caucasus Federal University: policy of forced growth. Accreditation in education, no. 5 (73), pp. 48-53.

Matishov G.G. (ed.), 2012. Problems of socio-economic and ethno-political development of the southern microregion. Rostov-on-don, Southern Scientific Center of RAS.

Neophytes in the Stavropol region have become a serious problem. Stavropol region TV. 2018. June 20. URL: https://stavropolye.tv/news/ state/112102 (accessed 27 April 2019).

Nikolaev K., 2019. Maria Zakharova danced lezginka at the youth forum "Mashuk-2019". Evening Moscow, 22.08.2019. URL: https://vm.ru/news/ 741851-mariya-zaharova-stancevala-lezginkuna-molodezhnom-forume-mashuk-2019 (accessed 20 April 2019).

Religion and nationalities: portal of government of the Stavropol territory. URL: http://www.stavregion.ru/ stat/social/religion (accessed 27 April 2019).

Sazonov E., 2013. In Stavropol shot dancers lezginka. Russian Explorer, 8 August. URL: http:// 
Г.Д. Гриценко. Этнорелигиозность городского пространства в контексте социокультурной стабильности

www.rus-obr.ru/ru-web/26008 (accessed 20 April 2019).

Sergutina G. 95 out of 100 residents of the Stavropol region positively assess the state of interethnic relations. MK-Caucasus, 26 June 2018. URL: https:// kavkaz.mk.ru/social/2018/06/26/pravitelstvostavropolskogo-kraya-sumelo-dobitsya-realnykhuspekhov-v-garmonizacii-mezhnacionalnykhotnosheniy-v-regione.html (accessed 20 April 2019).
In Stavropol arrested materialise the lezginka dancers. Stavropol.TV. URL: https://stavropolye.tv/ news/35300 (accessed 20 April 2019).

Timchenko M., 2018. The most unhappy Muslims. Why neophytes choose radical Islam. Arguments and Facts, no. 31, 6 August. URL: https://stav.aif.ru/ society/person/samye_neschastnye_musulmane pochemu_neofity_vybirayut_radikalnyy_islam (accessed 20 April 2019).

\section{Information about the Author}

Galina D. Gritsenko, Doctor of Sciences (Philosophy), Professor, Department of Philosophy and Humanities, Stavropol State Medical University, Mira St., 310, 355017 Stavropol, Russian Federation; Chief Researcher, Federal Research Centre The Southern Scientific Centre of the Russian Academy of Sciences, Chekchov St., 41, 344006 Rostov-on-Don, Russian Federation, dissovet@rambler.ru, https://orcid.org/0000-0001-8281-7409

\section{Информация об авторе}

Галина Дмитриевна Гриценко, доктор философских наук, профессор, профессор кафедры философии и гуманитарных дисциплин, Ставропольский государственный медицинский университет, ул. Мира, 310, 355017 г. Ставрополь, Российская Федерация; главный научный сотрудник, Федеральный исследовательский центр Южный научный центр РАН, просп. Чехова, 41, 344006 г. Ростов-на-Дону, Российская Федерация, dissovet@rambler.ru, https://orcid.org/0000-0001-8281-7409 